\title{
A CIDADE A PARTIR DA INTERCULTURALIDADE: um estudo entre moradores de
}

\section{Sorocaba/SP}

\author{
José Aparecido Batista Junior ${ }^{1}$
}

\begin{abstract}
Resumo: Discutimos sobre o processo de formação da cidade sob a ótica intercultural, interessando o entrelaçamento da vida individual com a coletiva, com orientação e viés da comunicação e da cultura do consumo. As falas apresentadas serviu no entendimento do processo de formação dos bairros estudados, os trânsitos, os pertencimentos e as práticas do consumo na(da) cidade a partir do não hegemônico, assim ouvir a voz do subalterno é um método pertinente. Relacionamos o consumo e o cotidiano, perpassando por questões das disparidades econômicas, sobretudo em função da má distribuição da riqueza socialmente produzida. Ao ser orientado pela cultura do consumo, analisamos o cotidiano e o território em que o indivíduo vive, indo além do local de moradia.
\end{abstract}

Palavras-chave: Cidade; interculturalidade; cultura; comunicação.

Abstract: We discuss the process of formation of the city from the intercultural point of view, interesting the interweaving of individual life with the collective, with orientation and bias of communication and consumer culture. The speeches presented served to understand the process of formation of the studied districts, transits, belongings and practices of consumption in the city from the non-hegemonic, so listening to the voice of the subordinate is a relevant method. We relate the consumption and the daily, perpassando by questions of economic disparities, mainly due to the poor distribution of the socially produced wealth. When being guided by the culture of consumption, we analyze the daily life and the territory in which the individual lives, going beyond the place of dwelling.

Keywords: city; interculturality; culture; communication.

\section{Introdução e Metodologia}

Os resultados são parte da tese, em andamento, de doutorado em comunicação, oriundos da pesquisa nos bairros Nova Esperança e Ana Paula Eleutério, ambos de Sorocaba/SP. O interesse prioritário e o problema de pesquisa é analisar a cultura do consumo.

O consumo é um mecanismo de integração social em que possuir determinados produtos e ou acessar alguns serviços implicam na construção e reforço de identidades sociais, culminando no reconhecimento de um indivíduo como cidadão. Assim, estudar a cultura do consumo permite entender a relação entre consumo e cidadania como sugere García Canclini (2015a), além de ser tema pouco explorado pela área comunicacional e um campo fértil para as práticas transdisciplinares.

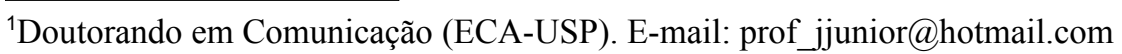




\begin{abstract}
Mas a escassez de estudos sobre consumo, que são antes pesquisas quantitativas de mercado e opinião, ainda permite avançar pouco na reformulação das relações entre comunicação massiva e recepção popular.

É, contudo, um espaço propício para o trabalho transdisciplinar. Trata-se de um problema comunicacional, que exige conceitos e instrumentos metodológicos mais sutis que os habitualmente usados nas pesquisas de público e de mercado. (GARCIA CANCLINI, 2015, p. 262).
\end{abstract}

O interesse no estudo sobre a cultura do consumo entre grupos não hegemônicos se dá em função de permitir entender em profundidade como as camadas populares se articulam para se sentirem pertencentes aos demais estratos sociais, ultrapassando a perspectiva clássica da resistência. O motivo prioritário da pesquisa é trazer à análise as articulações das camadas populares que as incluam no cotidiano, hegemônico ou não, da cidade e da cidadania sob o viés da cultura do consumo, pois com a diversidade populacional e cultural da cidade entendemos que precisa haver não apenas a efetivação dos direitos à igualdade, mas legitimar os direitos à diferença (GARCIA CANCLINI, 2015a.).

Certeau (1998) tem papel fundamental na análise sobre o cotidiano e a cidade por compreender as formas como o sujeito se insere no mundo através da linguagem, de práticas comunicacionais, do consumo/circulação na cidade, as interações entre o sujeito e o mundo a partir de sua apropriação em relação aos espaços habitados.

Aqui território é o "lugar em que desembocam todas as ações, todas as paixões, todos os poderes, todas as forças, todas as fraquezas, isto é, onde a história do homem plenamente se realiza a partir das manifestações da sua existência" (SANTOS, 2007, p. 13) com respeito à construção histórica do sujeito.

A cidade ganha destaque pelo entrecruzamento das histórias, sem dominador ou passivo, formadas sob diferentes espaços e trajetórias fragmentadas (CERTEAU, 1998) e com influência da comunicação de massa, da cultura do consumo e dos interesses hegemônicos. Garantir condições para a movimentação de onde se vive é vital para a promoção da locomoção autônoma entre os animais que se movem, que para isso utilizam todos os seus sentidos (LYNCH, 1997). Quando se tem a soma: reside distante dos serviços + menor poder de consumo, temos como resultado $(=)$ o comprometimento da movimentação e do consumo da cidade, por ficar restrita a possibilidade geográfica, contribuindo para sua segregação. 
escassos à medida que a distância do centro aumenta. Além disso, o conjunto da população e das empresas utilizam, em alguma medida, os serviços disponíveis apenas no centro principal, de modo que a distância em que se encontram do referido centro determina seus gastos de transporte (em dinheiro e em tempo) cada vez que se deslocam até ele. (SINGER, 1982, p. 29)

Estudar a cidade aqui não é o resultado das análises geográficas, mas a interface das questões oriundas do cotidiano, do pertencimento, da interculturalidade por meio da interdisciplinaridade. Sabemos que a geografia influencia na dinâmica e no consumo da cidade, porém a inquietação é compreender as estratégias dos grupos não hegemônicos residentes em locais pouco visíveis e que não consigam consumir os produtos e ou os serviços que garantam sua cidadania sob a perspectiva da cultura do consumo.

\begin{abstract}
O fato de pertencer a um bairro, quando corroborado pela pertença a um meio social específico, vem a ser uma marca que reforça o processo de identificação de um grupo determinado. No nível da representação, "ser da Croix-Rousse" exclui de ser ao mesmo tempo dos Brotteaux ou da Presq'île, da mesma maneira que ser operário, filho de operário etc., exclui de pertencer a outras classes sociais que moram nos bairros ricos. Mas, por outro lado, esta fórmula integra aquele que a pronuncia em um processo de reconhecimento que mostra que o sistema territorial é correlativo do sistema relacional. Este processo autoriza a apropriação do espaço urbano enquanto ele é o lugar onde se encontram sem cessar a pertença social e as redes de itinerários urbanos que têm por função significá-la. (CERTEAU; GIARD; MAYOL, 2013, p. 84).
\end{abstract}

Para Milton Santos (1978, p. 145) "o espaço é um verdadeiro campo de forças cuja formação é desigual. Eis a razão pela qual a evolução espacial não se apresenta de igual forma em todos os lugares" (1978, p.122). O espaço seria como as estruturas sociais, mesmo que "submetido à lei da totalidade, dispõe de uma certa autonomia". Não é apenas uma instância social que se reproduz, mas também é uma base para a organização humana heterogênea de sua vida cotidiana.

A pesquisa de campo (PC) se tornou um método relevante por auxiliar na representação da cidade a partir da fala de quem a consome, investigando as tensões, as tramas e as negociações estabelecidas entre os grupos econômicos antagônicos, não hegemônico e hegemônico, não apenas pela resistência. Em outras palavras o empreendimento teórico é estudar a territorialidade, já que ela "se faz pelos significados e ressignificações que os sujeitos vão construindo em torno de suas experiências de vida em dado território" (KOGA, 2003, p.38). 
Os bairros Nova Esperança e Ana Paula Eleutério foram escolhidos para PC devido à similaridade entre as características sociais e econômicas, além da riqueza das distinções que vão além da geografia, sobretudo pelo seu processo de formação. Vale explicitar que ser assistente social no município também facilitou na escolha dos locais por conhecer e estar próximo aos bairros vulneráveis e estigmatizados. Como a experiência nas áreas destacadas era apenas profissional e o interesse era não ser reconhecido como representante do Estado passei os meses de julho e agosto de 2016, pelo menos 03 vezes por semana em diversos períodos por, minimamente, 02 horas frequentando instituições religiosas e não governamentais, comércio e os serviços coletivos e públicos disponíveis para minimizar o problema e começarem a me ver como um civil, me aproximar dos moradores e iniciar as observações do cotidiano e da circulação.

Entre os meses de setembro a dezembro de 2016 as visitas eram com a incidência de, pelo menos, uma vez por semana por 03 horas. Em fevereiro de 2017 iniciei as entrevistas e como o interesse sempre foi "ouvir" o cotidiano, considerei que no bairro Nova Esperança fosse preciso complementar, no detalhamento da observação sobre o uso do grafite na praça, com a entrevista de pessoas que a utilizavam e fossem grafiteiros; ocorrência não programada.

Os métodos utilizados visam garantir a liberdade para que a realidade possa ser observada sem preconcepções e ou julgamentos, com olhar sensível e escuta aplicada, o que só é possível com a flexibilidade na condução da pesquisa, mesmo entendendo que isso é prejudicado com o processo de formação do pesquisador (ROUANET, 1990).

Outra questão não planejada foi à inópia de entender a visão profissional sobre à existência de terrenos vazios próximo ao Jardim Ana Paula Eleutério. Então, entrevistamos 03 corretores de imóveis para que pudessem externar os motivos pelos quais isso ocorria e complementar os dados.

Apoiado por uma instituição não governamental que atua em ambos bairros e que atende núcleos familiares em situação de vulnerabilidade econômica, aproveitei a realização de uma reunião com os assistidos para apresentar o estudo e convidá-los para participar das entrevistas. Os sujeitos que aceitaram tinham receio de participar por, sobretudo, dizerem suas opiniões e sentimentos em relação ao bairro e acessos aos serviços, o que gerou temor em sanções nos atendimentos das políticas públicas que faziam parte; em função do contexto entendi que a melhor solução seria utilizar nomes fictícios para deixá-los mais livres. Solicitei 
para se darem um nome por afinidade, mas deixavam a meu encargo, assim optei em identificá-los com nomenclaturas de flores. Segue a planilha que esboça algumas características pessoais dos que aceitaram serem entrevistados:

Nova Esperança

\begin{tabular}{|l|c|c|c|l|}
\hline $\begin{array}{c}\text { Nome de } \\
\text { identificação }\end{array}$ & Idade & $\begin{array}{c}\text { Tempo de moradia } \\
\text { no bairro }\end{array}$ & Grau de escolaridade & $\begin{array}{c}\text { Renda per capita - } \\
\text { média }\end{array}$ \\
\hline Girassol & 64 & +45 anos & Alfabetizado & $\mathrm{R} \$ 120,00$ \\
\hline Verbena & 77 & +55 anos & Analfabeta funcional & $\mathrm{R} \$ 135,00$ \\
\hline Hortência & 49 & +45 anos & Ensino Fundamental & $\mathrm{R} \$ 190,00$ \\
\hline Flox & 30 & +25 anos & Ensino Médio & $\mathrm{R} \$ 90,00$ \\
\hline Jacinto & 17 & 17 anos & $7^{\circ}$ ano (parou) & $\mathrm{R} \$ 70,00$ \\
\hline Delfim & 15 & 15 anos & $2^{\circ}$ ano do Ensino Médio & $\mathrm{R} \$ 110,00$ \\
\hline Tulipa & 25 & 25 anos & Cursa Ensino Médio & $\mathrm{R} \$ 65,00$ \\
\hline
\end{tabular}

Ana Paula Eleutério

\begin{tabular}{|l|c|c|c|l|}
\hline $\begin{array}{c}\text { Nome de } \\
\text { identificação }\end{array}$ & Idade & $\begin{array}{c}\text { Tempo de moradia } \\
\text { no bairro }\end{array}$ & Grau de escolaridade & $\begin{array}{c}\text { Renda per capita - } \\
\text { média }\end{array}$ \\
\hline Violeta & 60 & 20 anos & Analfabeta & $\mathrm{R} \$ 170,00$ \\
\hline Rosa & 55 & 19 anos & $\begin{array}{c}\text { Ensino Fundamental } \\
\text { Incompleto }\end{array}$ & $\mathrm{R} \$ 90,00$ \\
\hline Cravo & 61 & 20 anos & $\begin{array}{c}\text { Ensino Fundamental } \\
\text { Incompleto }\end{array}$ & $\mathrm{R} \$ 100,00$ \\
\hline Gardênia & 25 & +15 anos & $6^{\circ}$ ano (parou) & $\mathrm{R} \$ 80,00$ \\
\hline Gérbera & 26 & 20 anos & $6^{\circ}$ ano (parou) & $\mathrm{R} \$ 41,00$ \\
\hline Clorofito & 32 & 10 anos & Cursa ensino Superior & $\mathrm{R} \$ 120,00$ \\
\hline Goivo & 34 & 25 anos & Ensino Médio & $\mathrm{R} \$ 55,00$ \\
\hline Crisandália & 43 & 20 anos & Ensino Médio & $\mathrm{R} \$ 160,00$ \\
\hline
\end{tabular}

Outra complementação no método ocorreu durante a entrevista com a Sra. Hortência, pois seu filho nascido em 2007 acompanhava atento e com várias intervenções, assim legitimei sua participação, nomeando-o como Antúrio.

Resumidamente a inquietação conceitual pretende colaborar na perpetuação de pesquisas sobre a relação comunicação-consumo-cultura-cidade a partir da análise das negociações e apropriações realizadas por pessoas do grupo não hegemônico, sujeitos com voz, além de compreender a participação em que a comunicação de massa tem neste contexto, partindo de uma análise não específica apenas de uma disciplina (GARCIA CANCLINI, 2015 
$\mathrm{a}, \mathrm{b}, \mathrm{c})$.

\section{A cidade intercultural. Moro aqui ou lá?}

Os moradores do bairro Nova Esperança auxiliaram nas informações sobre o processo de formação prioritariamente por não haver dados oficiais, externando que a instalação de moradores foi intensificada entre as décadas de 1940 a 1960. No bairro Ana Paula Eleutério foi possível comparar os dados oficiais com as memórias dos moradores, por ser oriundo de um processo de desfavelamento da prefeitura em 1997 com cerca de 500 (quinhentas) famílias, ou seja, residir lá não era uma escolha direta, mas uma determinação do Estado que visava retirar as famílias da condição de risco e distribuí-las em lotes urbanizados, o que implicaria negativamente na relação com o cotidiano, com a cidade, com os aparelhos públicos e com o trabalho por grande parte dos moradores circularem com mais facilidade à região central antes da transferência.

O bairro Ana Paula Eleutério foi chamado de "Projeto Habiteto". Segundo a Secretaria de Cidadania, órgão responsável pela intervenção na época, “o desfavelamento, desenvolvido com o Projeto Habiteto, representa o direito de ter uma vida digna, ou seja, representa o direito à cidadania às pessoas que deles serão beneficiadas" (SECID, 1997 apud MEIRA, 2006, p. 69). Afirmativa contestável, pois segundo a Sra. Rosa, quando se mudou em 1998 não tinha condições financeiras de construir seu imóvel para residir, nem tão pouco "um cômodo e banheiro". Criado na região mais populosa, com menor renda per capita e com maior índice de criminalidade (zona norte) e na extremidade com difícil opção de comércio, oportunidade de trabalho, transporte e aparelhos públicos. Não se pensou na continuidade da interação dos indivíduos com a cidade, gerando a extrema invisibilidade dos moradores e higienização da cidade.

O Sr. Girassol, natural de Coronel Macedo/SP, veio para Sorocaba em 1968 trazendo os pais para ficarem em uma área que comprou com um "contrato de gaveta", pois o local pertencia ao governo e sua comercialização impedida de ser legalizada. Adquiriu em função do contexto, do preço e pelo tamanho, o que permitiria continuar plantando como fazia em sua cidade natal. Quando se mudou disse que não havia pavimentação, fornecimento de saneamento básico e energia elétrica, sendo comum terem poço, fossa e lampião a gás, mas 
disse estar habituado com a situação, já que em Coronel Macedo não era diferente. Quando chegou, estima que tivesse menos de 50 famílias.

\begin{abstract}
Que sofrimento fio do céu! No sítio também precisava pegar água, mas já estava acostumada, aqui para mim tudo era longe. Descia até na lagoa para pegar água, sozinha e com meus filhos. O marido? Dizia que tava trabalhando, mas depois descobri que ele arrumou outra família. Chegamo aqui, num tinha nem fossa, o vaso era um buraco no chão mesmo. Minhas crianças me deram trabalho, como ficavam doentes. (VERBENA).
\end{abstract}

Eu vim antes, comprei a área e como não tinha nada, conheci um comandante da polícia que me ajudou muito, deixou eu ficar na casa dele, enquanto construía um barraco com o dinheiro da venda de uma saca de milho que consegui em Coronel Macedo, era o único dinheiro que tinha. Que dificuldade, sem saber ler e escrever direito, perigoso o povo passar a perna em nóis, né? Fiz um quarto, a cozinha fora e um tipo de banheiro que ficava no ar livre, era o que tinha e fui buscar meus pais, eles não conheciam aqui. Logo meu pai morreu, acho que não gostou daqui, foi isso, muito rápida a morte. Mas era gostoso, ralei para saber lidar na cidade grande, com os espertos. (GIRASSOL).

Observamos que além do improviso em relação ao acesso aos itens básicos, fica claro a percepção distinta dos problemas ou visão da nova moradia, já que o Sr. Girassol escolheu morar no bairro, o que não ocorreu com a Sra. Verbena, dizendo que se mudou para Sorocaba apenas para acompanhar o marido, do qual pouco tempo depois separou-se.

O Sr. Girassol disse também que no ano em que se mudou para Sorocaba já havia uma concentração de comércio no centro da cidade, porém quando decidiu comprar o local a proximidade com o centro não foi um fator primordial, e sim por acreditar que os pais teriam ali uma vida similar com a de Coronel Macedo. Todavia salientou que com o passar do tempo a distância com o centro contribuiu no acesso ao centro comercial e pelas oportunidades de trabalho, o que se tornou um fator positivo.

Questões econômicas, globalizatórias e os avanços nos meios de transportes e de comunicação intensificaram os cruzamentos das pessoas de diferentes nacionalidades e regiões, com culturas distintas a um ambiente de convívio comum.

A interculturalidade surge a partir deste contexto, representando a relação democrática entre pessoas com formação dispare não de forma passiva, mas com negociações pulsantes. Pressupõe o envolvimento das diferenças com o diálogo no processo de convivência, pois o que se quer é que as diferenças sejam reconhecidas e que participem no cotidiano para que não fiquem no isolamento e no distanciamento do dia a dia, ultrapassando a visão que entende 
o que é de quem, porque a preocupação é compreender as negociações interculturais e identificar os prejuízos no convívio e objetivar a conversa dos diferentes, reconhecendo que são diferentes e não desiguais (GARCIA CANCLINI, 2015b).

O Sr. Girassol, ao falar "conheci um comandante da polícia que me ajudou muito, deixou eu ficar na casa dele" pode ser identificado como o "homem livre" de Garcia Canclini (2015c), pois não era nem latifundiário e nem escravo, dependia do favor do poderoso, e dada a diferença de tempo, é possível fazer uma analogia entre a vivência da "liberdade" e a política do favor.

\begin{abstract}
O favor se prolonga em outras áreas da vida social e envolve os outros dois grupos na administração e na política, no comércio e na indústria.

O favor é tão anti-moderno quanto a escravidão, porém "mais simpático" e suscetível de unir-se ao liberalismo por seu componente de arbítrio, pelo jogo fluido de estima e autoestima ao qual submete o interesse material. (GARCIA CANCLINI, 2015c, p. 76).
\end{abstract}

A remuneração do trabalhador com a industrialização, a globalização e o sistema econômico capitalista também ganhou uma roupagem de favor, com isso as relações sociais, pessoais e o acesso aos direitos legalmente instituídos são afetadas. $\mathrm{O}$ favor é um exercício para a dependência.

Querer estar, permanecer, construir e se identificar com espaços, com a interação e com a interculturalidade, são meios primorosos para a construção da cultura e da convivência, o que não significa que se traduz em passividade e pacificidade, pois se consegue por meio do reconhecimento das diferenças.

O que Mikhail Bakhtin investiga é aquilo que na cultura popular, ao opor-se à oficial, a une, aquilo que, ao constituí-la, a segrega. Por isso seu estudo centra-se na investigação do espaço próprio, que é a praça pública - "o lugar no qual o povo assume a voz que canta" - e o tempo forte que é o Carnaval. A praça é o espaço não segmentado, aberto à cotidianidade e ao teatro, mas um teatro sem distinção de atores e espectadores. (MARTÍN-BARBERO, 2013, p. 101).

Os entrevistados chamaram a atenção para a questão da interação entre os vizinhos e a adaptação ao novo ambiente de moradia.

Mudei para cá [Nova Esperança] na década de 1970 com meus pais, era legal, 
descíamos onde hoje é a praça para brincar e nadar, porém hoje acabou tudo. Tem a praça, mas não dá para usar direito, muita droga rola solta, aí meus filhos só ficam dentro de casa. (HORTÊNCIA).

Minha diversão é aqui em casa mesmo, minha mãe não deixa eu sair e jogar bola na praça, tem muito nóia. Ela tem medo que eu use droga. Queria aproveitar o campo e jogar bola. Quando tinha a guarda era melhor. (ANTÚRIO).

A praça? Poxa rapaz, tem umas árvores boas, né? Mas tem hora para usar, muita maconha e sem vergonha. Bom poder jogar um dominó o dia todo lá. Mas como não dá, saio de ônibus e fico em casa arrumando alguma coisa para fazer. (GIRASSOL).

A Sra. Hortência era criança quando mudou-se e construiu sua casa no fundo do terreno dos pais e Antúrio é nascido no bairro e por esta razão, ambos falam do mesmo local, porém com percepções distintas em função do tempo e da dinâmica cotidiana.

Nas falas, é notada a representatividade que o espaço da praça "Pedro de Godoy" ou "Praça do Tancão", sobretudo entre os mais antigos do bairro Nova Esperança, teria, se pudessem utilizá-la com tranquilidade e como um local de interação social; porém, como o receio da violência é maior, não a utilizam. Respaldado no Google Maps apresentamos a seguir sua fotografia área para melhor ilustração:

Figura 1 - Praça "Pedro de Godoy" - Nova Esperança

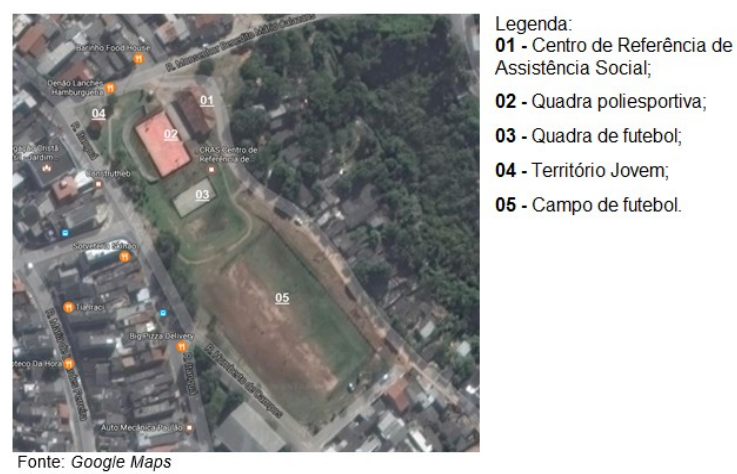

Fonte: Google Maps.

Com espaço amplo a respectiva praça conta com 05 principais atividades como destacado, porém onde é o “Território Jovem”, até meados de 2014, conforme Antúrio, era o posto descentralizado da Guarda Civil Municipal (GCM). Porém, na contramão do entendimento de Bakhtin, esta praça não pode ser identificada como o "lugar no qual o povo assume a voz que canta" em função de haver certo controle e uso do poder público, já que 
nela funciona o Centro de Referência de Assistência Social (CRAS), aparelho público que atende as demandas sociais do bairro e região via ações sociais preventivas, além do atendimento a outras políticas públicas.

A instalação do CRAS pode contribuir para desassociar a praça do lazer. Alguns a denominam como "a praça do CRAS" ou a outro aparelho público que tinha no local, como o posto da GCM: "Qual praça? A do CRAS?” (HORTÊNCIA). “A Praça do CRAS? A do ‘Tancão'?” (GIRASSOL). “A que tinha o posto da guarda?” (FLOX).

O que deveria ser uma área de livre pertencimento é utilizada para executar atividades e interesses da administração pública municipal. Contribuindo com esta percepção cumpre dizer que na rua em frente ao "Território Jovem" foi instalado por mais de 01 ano um trailer da Secretaria de Habitação e Regularização Fundiária para tratar da formalização documental da titularidade dos terrenos, reforçando a utilização e a circulação para fins burocráticos, legais e formais. Martín-Barbero (2013) ainda respaldado em Bakhtin, diz que:

\begin{abstract}
O que caracteriza a praça [é] sobretudo uma linguagem; ou melhor: a praça é uma linguagem, 'um tipo particular de comunicação', configurado a partir da ausência das construções que especializam as linguagens oficiais, seja a da Igreja, a da Corte ou a dos tribunais". Uma linguagem na qual predominam, no vocabulário e nos gestos, as expressões ambíguas, ambivalentes, que não apenas acumulam e dão razão ao proibido, mas também, ao operar como paródia, como degradaçãoregeneração, 'contribuíam para a criação de uma atmosfera de liberdade'. Grosserias, injúrias e blasfêmias revelam-se condensadoras das imagens da vida material, e corporal, que liberam o grotesco e o cômico, os dois eixos expressivos da cultura popular. (MARTÍN-BARBERO, 2013, p. 101-02).
\end{abstract}

Os bairros estudados são estigmatizados como perigosos, corroborando com a ideia de que os meios massivos acusam "as megalópoles de gerar anonimato, imaginou-se que os bairros produzem solidariedade, os subúrbios crimes e que os espaços verdes relaxam..." (GARCIA CANCLINI, 2015c, p. 285). Sobre estigma respaldamos nos estudos de Soares (2009) que relata que é diferente de preconceito, já que os preconceitos "operam como julgamentos a priori realizados sobre um grupo ou um indivíduo" e os estigmas, "mais abrangentes, se encontram na base dos preconceitos" (SOARES, 2009, p. 02). Utilizamos estigma por ser uma marca visível, "podendo ser tanto um sinal infamante ou vergonhoso, como um sinal natural do corpo" (SOARES, 2009, p. 02). Se há o estigmatizado é porque há o que é considerado "normal", que por sua vez tem legitimidade social, com isso a distinção e 
a dicotomia: superior e inferior.

A partir desta análise, questionei na entrevista sobre o motivo pelo qual este estigma ocorre, a mídia e a prefeitura foram destacados como representantes deste pensamento.

Primeiro, porque aqui foi pobre que criou. Não sei, mas acho que todo mundo veio do povo. A gente grita, fala alto, conversa com os vizinhos, anda a pé, xinga o pessoal do posto ou da escola se acontece alguma coisa ruim. Tem catador de reciclagem, gari, trabalhador que coloca a mão na massa, não esse pessoal que fica atrás de uma mesa e com gravata. Se for ver a gente serve eles, né? Bom, ladrão também tem, mas tem em todo lugar, a diferença que aqui vira notícia da polícia. (FLOX).

Meu filho, aqui é visto assim porque a televisão só mostra a bandidagem e violência, mas tem em toda cidade isso. Somos vistos como coitados pela prefeitura e que sempre precisam de alguma coisa, caridade. Aqui pode ter pobre, mas tem mais pessoa com pensamento pobre. (GIRASSOL).

Faço curso de inglês na cidade e tenho vergonha no começo quando não conheço a pessoa de falar que moro aqui. As casas são estranhas, feias. Moro no fundo da minha avó. Quando falei meus colegas ficaram com medo ou nem sabia onde era o Nova Esperança, daí fui mostrar na internet, que vergonha, só notícia ruim (risos). (ANTÚRIO).

A distinção laboral da Sra. Flox pode ser relacionada com a arte representada por Raymond Williams (1979) ao dizer que serve para separá-la do trabalho "mecânico", enaltecendo a distinção de classe, coisas superiores dos negócios “ordinários”, o primeiro com objetos para os gostos dos homens livres e o segundo ao trabalho manual e com máquinas.

Antúrio fala indiretamente da maneira como as edificações são realizadas no bairro, porém são estratégias assumidas para sanar o problema da moradia. Garcia Canclini (2015c) demonstra esta iniciativa com bons olhos, pois é a reflexão da brilhante imaginação na construção dos imóveis, utilizando itens que seriam descartados, sobretudo em função das práticas manuais adquiridas nos ofícios desenvolvidos e solucionar os problemas que surgem de forma apropriada ao contexto e modo de viver. Invenções do cotidiano, em táticas e astúcias usadas como arte pelo fraco (CERTEAU, 1998).

A Sra. Flox retrata a disparidade imposta pela divisão social do trabalho: de um lado o trabalhador e empresário; de outro os ocupantes de funções menos garantidoras de visibilidade, embora de extrema valia para o curso do cotidiano, como são os catadores e coletores de resíduos sólidos. Cabe salientar a este respeito que, o incentivo ao consumo gera montanhas de resíduos, seja em aterros sanitários ou a céu aberto. 
Embora não seja de interesse direto desta pesquisa, o grafite esteve por muito tempo atrelado à pobreza, ao vandalismo, a periferia, a falta de educação, a sujeira, entre outras questões. "O grafite é para mestiços da fronteira, para as tribos urbanas da Cidade do México, para grupos equivalentes de Buenos Aires ou Caracas, uma escritura territorial da cidade, destinada a afirmar a presença e até a posse sobre um bairro" (GARCÍA CANCLINI, 2015c, p. 336). O que chamou a atenção na pesquisa foi a inexistência de grafites na área em que o poder público administra diretamente, como vemos a seguir:

Figura 2 - Praça "Pedro de Godoy" - Nova Esperança

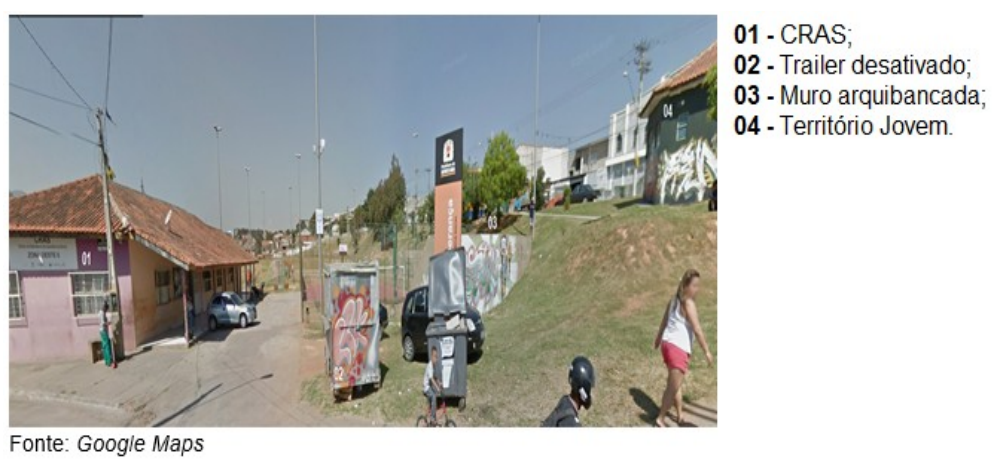

Fonte: Google Maps

É notado que apenas o Centro de Referência de Assistência Social (CRAS) não está grafitado. Embora não estivesse no planejamento metodológico, com a percepção oriunda das visitas ao local considerei viável questionar os jovens que estavam ali sobre o assunto e dois quiseram contribuir com a análise, um com 17 anos e outro com 15 anos, respectivamente. "Eu ajudei no grafite do Território Jovem e do muro, porque é nosso. O CRAS? Olha, nem sei porque tá aqui. Nem sei o que faz, quer dizer, tem a ver com o Bolsa Família e comida." (JACINTO). “Acho que porque não pertence a nós. O CRAS é da prefeitura, o pessoal nem sai de lá de dentro direito, os outros [locais grafitados] é daqui mesmo. Sem falar que perigoso acharem que isso é coisa de bandido.” (DELFIM).

Percebem que são vistos como sujeitos à margem e ou pessoas inferiores entre os que não moram no bairro. Cabe destacar que as alterações e as transformações dos cenários originais urbanos através de diversas manifestações (música, teatro, leituras e narrativas, dança) e a arte popular urbana, o que inclui os grafites, as pichações, os stickers, fazem parte das redes de sociabilidade, institucionalizados ou não, típicas da juventude. Estas ações 
permitem que se tornem atores sociais, participantes e interventores nos processos que estão inseridos na comunidade, como também nos espaços públicos das cidades em que residem. Tais ações "adquirem um caráter político por sua intencionalidade e pelas formas por meio das quais se apropriam dos espaços públicos transformando-os, mesmo que efemeramente, em 'lugares seus"' (BORELLI; ROCHA, 2008, p. 32-33).

Ainda que o CRAS esteja tão próximo, a relação não é dada de forma compartilhada e participativa. É um local público que não é utilizado por todos, por talvez não fazer sentido aos que desconheçam seus objetivos e ou as ações não atenderem as expectativas dos residentes.

As indústrias midiáticas com as inovações tecnológicas no campo das comunicações e do transporte facilitaram a circulação de pessoas, de bens simbólicos, de objetos e dos significados implicando no contato mais dinâmico entre culturas que antes não conseguiriam tal interação. O que não significa que todos pensem e hajam da mesma forma. Não podemos perder de vista o conceito da interculturalidade para que não caíamos na homogeneização das culturas e representações.

$\mathrm{Ou}$ as indústrias culturais e os heterogêneos modos de recepção em culturas diversas: o que ocorre quando se fala da telenovela como gênero latino-americano, quando, na realidade, existem muitas diferenças entre as brasileiras, as colombianas e as mexicanas, muitos olhares de mulheres, de homens, de nostálgicos da família, assim como de críticos das reduções do social aos artifícios do melodrama. (GARCIA CANCLINI, 2015b, p. 171).

No caso deste estudo percebemos isso quando os moradores de outras localidades vêm residir em Sorocaba e trazem seu cotidiano que é negociado no novo lugar: "o terreno era grande e dava para plantar alguma coisa, um pouco parecido com Coronel Macedo" (GIRASSOL).

\section{Consumo da cidade e considerações finais}

Além das diferenças do processo de formação dos bairros, apresentamos a influência que a localização traz aos sujeitos em relação ao consumo da cidade. O centro da cidade torna-se uma referência por haver diversos serviços que atendem as demandas cotidianas de 
todos nós, além de grande possibilidade de trabalho, formal ou não.

Tabela 1 - Distância entre os bairros e o centro de Sorocaba/SP

\begin{tabular}{|l|c|c|c|}
\cline { 2 - 4 } \multicolumn{1}{c|}{} & Centro - a pé & Centro - carro & Centro - bicicleta \\
\hline Nova Esperança & $4,3 \mathrm{Km}$ & $5,9 \mathrm{Km}$ & $4,3 \mathrm{Km}$ \\
\hline Ana Paula Eleutério & $10,4 \mathrm{Km}$ & $11,9 \mathrm{Km}$ & $10,5 \mathrm{Km}$ \\
\hline
\end{tabular}

Fonte: Google Maps

Em função das particularidades e ineficiência dos serviços públicos há o aumento do fluxo do transporte individualizado; processo que culmina em ruas saturadas, pessoas com pressa para cumprir os horários, profissionais ou diversões programadas, "quase sempre conforme a renda econômica" (GARCÍA CANCLINI, 2015c, p. 288). Portanto, morar longe do centro comercial, significa ir contra a lógica do privado e do mercado, pois ele "reorganiza o mundo público como palco do consumo e dramatização dos signos de status" (GARCÍA CANCLINI, 2015c, p. 288). O tempo gasto no trajeto de um bairro ao centro da cidade é muito díspar, implicando na perda de muito tempo no percurso.

\begin{abstract}
A cidade é o palco de atores os mais diversos: homens, firmas, instituições, que nela trabalham conjuntamente. Alguns movimentam-se segundo tempos rápidos, outros, segundo tempos lentos, de tal maneira que a materialidade que possa parecer como tendo uma única indicação, na realidade não a tem, porque essa materialidade é atravessada por esses atores, por essa gente, segundo os tempos, que são lentos ou rápidos. Tempo rápido é o tempo das firmas, dos indivíduos e das instituições hegemônicas e tempo lento é o tempo das instituições, das firmas e dos homens hegemonizados. A economia pobre trabalha nas áreas onde as velocidades são lentas. Quem necessita de velocidades rápidas é a economia hegemônica, são as firmas hegemônicas. É para esta classe que tem significação uma avenida como a dos Bandeirantes, ou estradas como a dos Bandeirantes e a Anhanguera, que são estradas que sobretudo interessam aos agentes hegemônicos e às pessoas ricas que usam melhor, do seu ponto de vista, essas estradas. Do aeroporto ao centro da cidade vai-se muito depressa, criam-se condições materiais para que o tempo gasto na viagem seja curto. Já entre os bairros vai-se mais devagar, no sentido de que não há uma materialidade que favoreça o tempo rápido. (SANTOS, 2001, p. 22).
\end{abstract}

Guiados pelos interesses hegemônicos, a organização da dinâmica de fluidez e agilidade do trajeto se estabelecem conforme interesses particulares, ou seja, trazem à tona o "tempo rápido" (SANTOS, 2001). Nos bairros, resta a "economia pobre", com a velocidade de circulação lenta por não estarem entre os interesses dos detentores dos meios de produção. Porém, ali está instalado o maior número de trabalhadores das instituições hegemônicas. 
Em se tratando do tempo, é notado que o tempo restante é menor entre os que estão em situação de invisibilidade do que os pertencentes ao grupo hegemônico (DOUGLAS; ISHERWOOD, 2013) como vemos na tabela a seguir:

Tabela 2 - Tempo gasto no trajeto entre os bairros e o centro de Sorocaba/SP

\begin{tabular}{|l|c|c|c|c|}
\cline { 2 - 5 } \multicolumn{1}{c|}{} & Centro - a pé & Centro - carro & Centro - bicicleta & Centro - ônibus \\
\hline Nova Esperança & $54 \mathrm{~min}$. & $17 \mathrm{~min}$. & $19 \mathrm{~min}$. & $32 \mathrm{~min}$. \\
\hline Ana Paula Eleutério & $02 \mathrm{~h} 10$ & $29 \mathrm{~min}$. & $37 \mathrm{~min}$. & $40 \mathrm{~min}$. \\
\hline
\end{tabular}

Fonte: Google Maps

Considerando as informações disponibilizadas nas tabelas 01 e 02 , verificamos a variação da distância e de tempo gastos. A distância a pé do bairro Ana Paula Eleutério é $58,65 \%$ superior ao do Nova Esperança; com o carro a diferença diminui para 50,42\% e com a bicicleta a disparidade chega a 59,05\%. Em se tratando do tempo gasto no trajeto dos bairros ao centro de Sorocaba temos: $58,46 \%$ a pé; $41,38 \%$ de carro e $48,65 \%$ de bicicleta.

Com base na tabela 02 possuir veículo próprio, por exemplo, representa um significado maior que um "gasto inútil” ou “desnecessário", permite uma melhor circulação na cidade, já que não temos acesso a transporte coletivo que atenda totalmente nossas necessidades, culminando na individualização do transporte de maior quantia de veículos nas ruas. “Aqui dá pra fazer as coisas até sem carro. Não é muito longe do centro, dos bancos. Dá pra ir até no shopping a criançada sem gastar nada" (risos). (FLOX).

\footnotetext{
O que é da gente sem carro aqui? Fiz um empréstimo pra comprar um carrinho. Pelo menos dá para fazer compra nos mercado e pegar promoção, nem precisa esperar para trazer. Acho que depende do mercado nem trazem, porque pizza não entregam aqui não. (CRAVO).
}

Tomando como exemplo o bairro Ana Paula Eleutério, o tempo gasto é reduzido em 01h41, considerando a hipótese que o indivíduo trabalhe 05 dias por semana, com o veículo automotor, seria economizado $08 \mathrm{~h} 25$ semanalmente do bairro ao centro comercial. A mesma lógica cabe quando comparamos o uso do carro e do ônibus, teríamos um declínio de 27,50\% ou 11 minutos diariamente, semanalmente o sujeito economizaria 55 minutos do trajeto.

Os empregadores desejam que seus futuros empregados nadem em vez de caminhar 
e pratiquem surf em vez de nadar. O empregado ideal seria uma pessoa sem vínculos, compromissos ou ligações emocionais anteriores, e que estabelecê-los agora; uma pessoa pronta a assumir qualquer tarefa que lhe apareça e preparada para se reajustar e refocalizar de imediato suas próprias inclinações, abraçando novas prioridades e abandonando as adquiridas anteriormente; uma pessoa acostumada a um ambiente em que "acostumar-se" em si - a um emprego, habilidade ou modo de fazer as coisas - é algo malvisto e, portanto, imprudente; além de tudo, uma pessoa que deixará a empresa quando não for mais necessária, sem queixa nem processo. (BAUMAN, 2008, p. 18).

Dentro da lógica hegemônica visa-se que a vida pessoal do trabalhador fique em segundo plano, sua prioridade deve garantir o bem da empresa e dos empregadores. Possuir veículo próprio ou investimento nos transportes coletivos e ciclovias permitirá ao cidadão maior fluidez na cidade, além do menor gasto de tempo nos trajetos.

Douglas e Isherwood (2013) dizem que a sobra de tempo dos pobres imaginada pelos detentores dos meios de produção está associada ao fato de não estarem plenamente inseridos no processo de produção e de consumo, já que sem poder de compra é dificultado um padrão imobiliário elevado dos imóveis, troca de roupas, entre outros, e, "porque a roda social reduzida consome menos tempo" (DOUGLAS; ISHERWOOD, 2013, p. 261).

A perspectiva hegemônica interfere até na disposição do tempo livre dos indivíduos, uma vez que as melhoras são realizadas para priorizar a otimização das rentabilidades.

Uma organização diferente do "tempo livre", que o transforma em prolongamento do trabalho e do lucro, contribui para essa reformulação do público. Dos cafés da manhã de trabalho ao trabalho, aos almoços de negócios, ao trabalho, para ver o que nos oferece a televisão em casa, e alguns dias aos jantares de sociabilidade rentável. (GARCÍA CANCLINI, 2015c, p. 288).

Portanto, nos bairros como na cidade é preciso que as políticas públicas pensem na interculturalidade, pois encontramos pessoas com formações distintas que se cruzam, se relacionam e negociam sentidos, como dito, o que não significa que seja de forma pacífica ou resistente. O interesse deve ser na análise das negociações. "Olha aqui tem gente de todo tipo: pobre, rico e que se acha rico (risos). Tem evangélico, católico, biscate, viado, travesti e homem que não vale o que come." (FLOX).

Fator desafiante para que o Estado pense as políticas democráticas, já que não se trata de proporcionar acesso aos bens "legítimos", mas a discussão sobre a compreensão de cultura e os direitos do diferente. A democracia formal não está na mesma linha das diferenças 
baseadas em desigualdades, porque não é apenas garantir as oportunidades iguais, pois

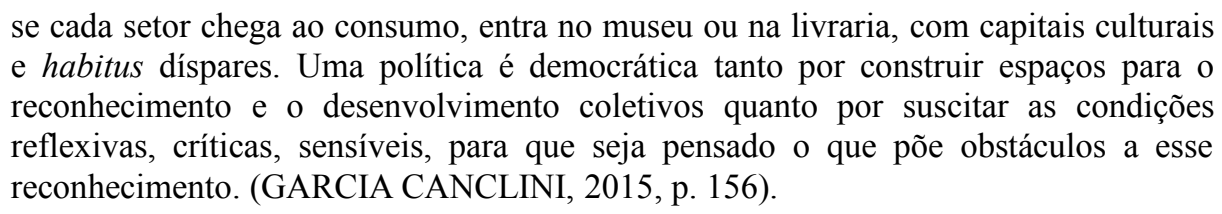

\section{Referências}

BAUMAN, Zygmunt. Vida para o consumo: a transformação das pessoas em mercadoria. Tradução Carlos Alberto Medeiros. Rio de Janeiro: Zahar, 2008.

BORELLI, Silvia Helena Simões; ROCHA, Rose de Melo. Juventudes, midiatizações e nomadismos: a cidade como arena. In: Revista Comunicação, Mídia e Consumo. São Paulo: ESPM, 2008, n. 13, v. 05, p. 27-40.

CERTEAU, Michel de. A invenção do cotidiano: artes de fazer. 3. ed. Tradução Ephaim Ferreira Alves. Petrópolis: Editora Vozes, 1998.

CERTEAU, Michel de; GIARD, Luce; MAYOL, Pierre. A invenção do cotidiano: 2. Morar, cozinhar. 12. ed. Petrópolis: Vozes, 2013.

DOUGLAS, Mary; ISHERWOOD, Baron. O mundo dos bens: para uma antropologia do consumo. Tradução Plínio Dentzien. 2. ed. Rio de Janeiro: Editora UFRJ, 2013

GARCÍA CANCLINI, Néstor. Consumidores e cidadãos: conflitos multiculturais da globalização. Tradução Maurício Santana Dias. 8. ed. Rio de Janeiro: Ed. EFRJ, 2015a.

GARCÍA CANCLINI, Néstor. Culturas híbridas: estratégias para entrar e sair da modernidade. Tradução Heloísa Pezza Cintrão, Ana Regina Lessa; Gênese Andrade. 4. ed. 7. reimp. São Paulo: EDUSP, 2015c.

GARCÍA CANCLINI, Néstor. Diferentes, desiguais e desconectados: mapas da interculturalidade. Tradução Luiz Sérgio Henriques. 3. ed. Rio de Janeiro: Ed. EFRJ, 2015b.

KOGA, Dirce. Medidas de Cidades: Entre Territórios de Vida e Territórios Vividos. São Paulo, Cortez Editora, 2003.

LYNCH, K. A imagem da cidade. São Paulo: Martins Fontes, 1997.

MARTIN-BARBERO, J. Dos meios às mediações: comunicação, cultura e hegemonia. Tradução Ronald Polito e Sérgio Alcides. 7. ed. Rio de Janeiro: UFRJ, 2013.

ROUANET, Sergio Paulo. Ética e antropologia. In: Estudos Avançados, 4(10). São Paulo: 
USP, 1990.

SANTOS, Milton. et. al. Território, territórios: ensaios sobre o ordenamento territorial. 3. ed. Rio de Janeiro: Lamparina, 2007.

SANTOS, Milton. O tempo nas cidades. 2001. Disponível em: $<$ http://www.laboratoriourbano.ufba.br/arquivos/arquivo-71.pdf $>$. Acessado em: 06/12/2016.

SANTOS, Milton. Por uma Geografia Nova. São Paulo: Hucitec, Edusp, 1978.

SINGER, Peter. O uso do solo urbano na economia capitalista. In: MARICATO, E. (Org.). A produção capitalista da casa (e da cidade) no Brasil industrial. São Paulo: AlfaOmega, 1982.

SOARES, Rosana de Lima. De palavras e imagens: estigmas sociais em discursos audiovisuais. In: Revista da Associação Nacional dos Programas de Pós-Graduação em Comunicação. E-compós. Brasília: n. 01, v. 12, 2009, p. 01-23.

WILLIAMS, Raymond. Marxismo e Literatura. Rio de Janeiro: Zahar, 1979. 